\title{
Development of RFID based Automatic Warehouse Management System: A Case Study of ROK industries Limited Kenya
}

\author{
Fabien Ngaboyimbere ${ }^{1}$, Judith Leo ${ }^{2}$, Kisangiri Michael ${ }^{3}$, and Dinah Muteteshe ${ }^{4}$ \\ Research Scholar ${ }^{1}$, Lecturer ${ }^{2}$ and Senior Lecturer ${ }^{3}$, Research Scholar ${ }^{4}$ \\ School of Computational and Communication Science and Engineering (CoCSE) \\ Nelson Mandela African Institution of Science and Technology (NMAIST) \\ Arusha, Tanzania
}

\begin{abstract}
In the supply chain and logistics industry, the precision of the data assets inventory plays a crucial role in warehouse activities. The operations like storage locations arrangement, inventory management, and maintaining the flow of incoming and out coming goods lead to the success of the warehouse. Nowadays, most people are preferring online shopping all over the world because it is faster than local trade. Thus, there's massive information in the supply chain and logistics sector to explore in order to improve operations of the warehouse such as receiving, ordering, shipping, storage assignment to facilitate the automation in the warehouse. This study is conducted to improve warehouse activities by automating storage and inventory management. A software program was developed with sets of rules, and an algorithm to optimize the inventory operations with the help of RFID technology. The predefined rules help in giving priorities to some of the selected products to store and retrieve in indicated location. The UHF RFID reader is attached to the entrance of the gate of the warehouse to facilitate the reading of incoming goods. Once the goods arrive in the warehouse, the storage location function will assign to each product the storage location and update status in the database. A handheld reader facilitates inventory management and communicates with the application via a wireless network and finally store data in the database for future use. After developing this system, a test was conducted for testing the feasibility and applicability of the system. The output showed that the inventory management operation was made strides, and the correctness of inventory location increased from $72.8 \%$ to 99\%. The cycle time moreover decreases from 50 minutes to 18 minutes which is down to $28.79 \%$.
\end{abstract}

Keywords: RFID, Event Processor, Storage assignment, Automatic Pallet, Automatic shelf.

\section{INTRODUCTION}

Inventory management is one of the basic components of productive supply chain management that results in success in commerce. The inventory management decisions are dependent on the data assembled from computerized or manual control systems. In this manner, the programmed warehouses helped a lot in inventory management operations since they coordinated numerous functions and have focal points such as a speedier turnover speed, a low rate of item frailty, and the capacity to store more items in a smaller area.

However, most of organizations are considering the use of computerized warehouse because maybe they think that it is expensive and highly technological skills. The manual systems are used to handle warehouse activities in Kenya including ROK Industries. All operations are manual; items are stored in warehouse randomly on the ground or floor with no any modern procedure of products keeping during receiving process. The operator is supposed to be experienced enough in order to handle all warehouse activities which result in delaying the entire inventory management and source of a lot of errors [1]. In addition, it is also challenging in case the company has a big warehouse and complex customer orders. To overcome with the mentioned challenges, the automatic warehousing system can be integrated in the daily basis of warehouse activities. The modern strategies of product storage and record keeping could be replaced manual process. The automatic identification of storage/retrieval assignment for fast moving of product, a quick assignment of storage to incoming product in the warehouse will increase efficient and increase 
customer satisfaction. To address the aforementioned issues, RFID was proposed. To optimize warehouse activities, we propose an RFID-Automatic warehouse management system (RFID-AWMS) in this study.

The added values of this paper to existing works is to improve manual warehouse operations by using UHF RFID, computer software in between, and a wireless network. The RFID-AWMS automate all activities of a manual warehouse operations by automating storage location assignment to all coming product, real-time inventory operations, and proper use of shelves in the warehouse.

\section{RELATED WORKS}

\subsection{Warehouse management}

Most of warehouse activities comprise stock capacity, arrange item blending, cross-docking, and client's benefits [2]; [3] agreed to the reality by saying that an efficacy use of warehouse capacity and assets management increase the accuracy of warehouse and the benefits of customers. In this way, a tremendous a lot of wrings emphasizes the proper utilization of the warehouse, particularly on the automatic warehouse has increased. [4] said that the operations of warehouse may be categorized into two types: theoretical customers' orders picking and modelling as a workshop planning issue. Most of these ponders depend on the presumption that cannot maintain the traditional methods of object recognitions by making a difference on the variation of inventory management which is extreme verified manually. In the past years ago, RFID as advanced technology has finished up well known within the field of industry trading in the coordination of supply chain [5]. Therefore, increasingly supervisors take under consideration the appropriation of RFID to adjust the working taken a toll against the prerequisites on building digitalized store-houses.

Suryanto, T., Haseeb, M. et al., outlined the most of the important warehouse activities which include storage locations arrangement, inventory management, maintaining the flow of incoming and out coming products, and the end user satisfaction [6]. The more efficient use of warehouse space and equipment result in better accuracy and end user satisfaction [7]. Thus, a lot studies focuses on the utilization of the automated warehouse storage and retrieval assignment to improve inventory management rather than using manual system [8].

\subsection{Radio frequency identification}

According to the prototype of RFID and sensors network for the elder healthcare progress report, RFID application has been adopted by many organizations in the middle east last few years ago. The inventors categorized RIFD application area into four angles of applications which are innovative services, security issues, healthcare treating, and agricultural applications [8].

Nowadays, most companies are trying to improve their material flow by adopting RFID technology into their business operations. [9] examined the regard of RFID under imperfect stock data. [10] used RFID technology to collect data from retailer of products of one its major suppliers. In this study, the researcher explains the reason why business owners should integrate RFID technology in daily working operations. He said that this technology offers assistance to eliminate the data loss and delay of data flow without forgetting data sharing speed. Additionally, [11] also talks about how RFID-based object trucking technologies can be utilized to progress the permeability of information. [12] emphasized on the impact of RFID on the utilization of space in the warehouse (e.g., warehouse capacity) and planning in a complex manufacturing process. For more progressed inquire about on data innovation, we prompt the readers who are interested to conduct a survey on the information of [3] and [13]. [14] demonstrated that when RFID is well developed, tested and implemented in any company, the accuracy should be $100 \%$.

The researchers Qiao, Y et al., [15] in comparison of our work is the one closest our research, the authors designed an RFID based Automatic warehouse management system to automate warehouse operations. The main objective of their system is to automate warehouse activities by integrating RFID and Event Condition-Action(ECA) technology and optimization of the use programed forklift for quick transportations of products. The results after implementation of their system in Tobacco industry illustrate that the utilization of warehouse operation is maximized. However, our system has multiple functions compared to Wang's system. First of all, capacity of warehouse is enhanced through the adoption of drive in racks system to improve warehouse storage space of products. The forklift guided system embedded with handheld ultra-high frequency RFID reader facilitates forklift to move around in the racks of warehouse to easily place items order for shipping by loading or retrieving the pallets' tags stored in a particular storage Id. 


\section{RESEARCH METHODS}

\subsection{System design and Network Architecture}

The layout of the system shown in Figure 1 is composed with both hardware and software components. The hardware components consist of build-in antenna UHF RFID reader, RFID tags, RFID desktop readers, Arduino Uno board, and the wireless Local Area Access device while software components include a middle software, RFID adaptor and the handheld Reader Integrated System(HRIS). The middleware program plays a significate role among these components. It is the central pillar of the entire system. It is designed to control all activities and materials in the warehouse starting from receiving process, until the end of operation (i.e., product reach to customer). It has up to four sub modules which are Computerized Shelf Monitor, Storage/Retrieval manager, RFID reader intermediary application (reader adapter), and event processor manager. The data flow of RFID operation is under RFID reader adaptor control.

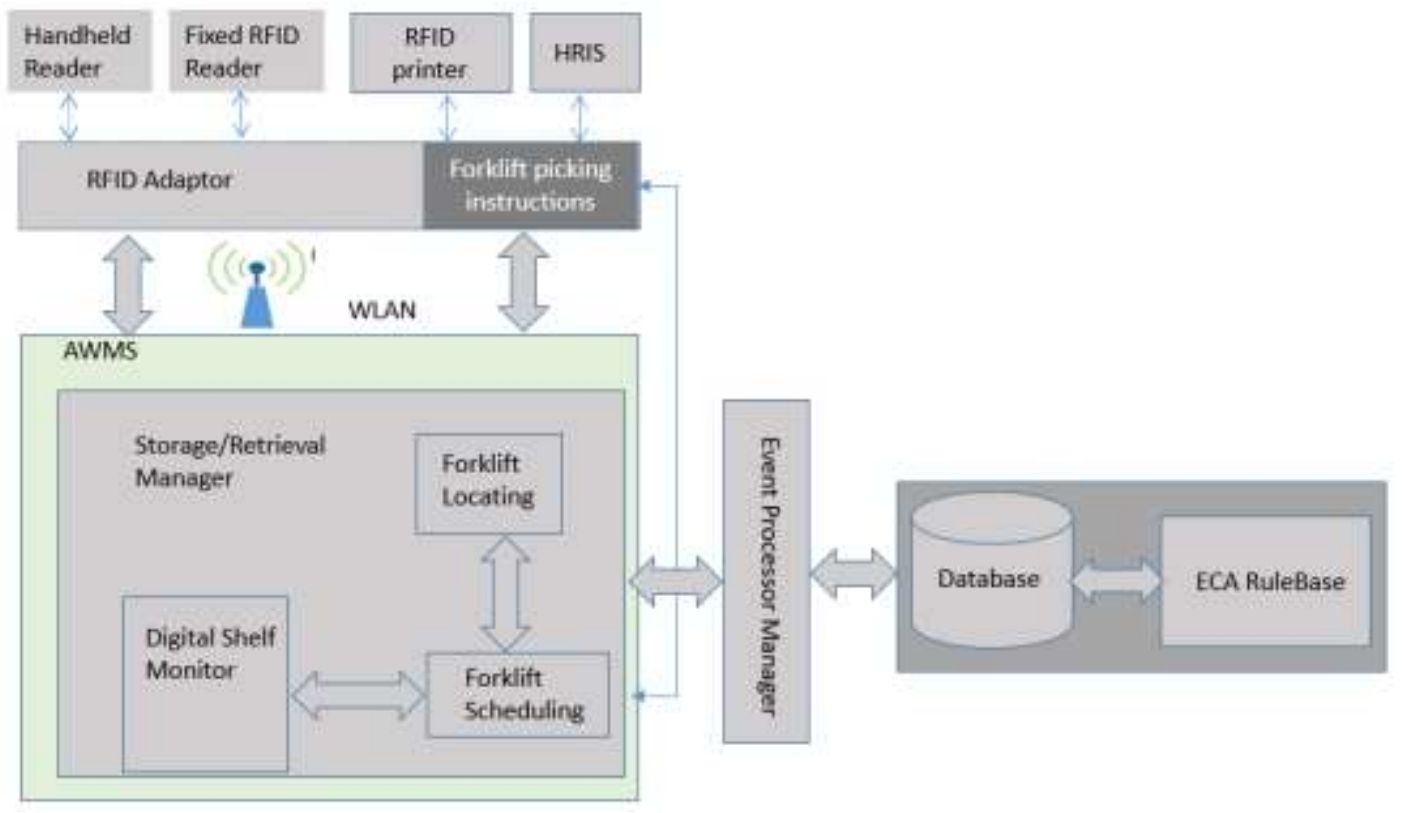

Figure 1. System architecture of RFID-AWMS

\subsection{Automatic Warehouse Management System (AWMS)}

The AWMS is a computer application designed based on software specifications provided by ROK authorities. It is composed of Computerized Shelf Management, storage location management, RFID reader intermediary application (reader adapter), and event processor management.

\subsection{Handheld RFID Reader terminal}

The Handheld RFID Reader used in our system contain the same functionalities like others UHF Personal Automatic Assistant(PDA). In addition, this PDA device has capability of reading and writing of all types of RFID tags. During packaging, the products specifications in form of pallet are attached to RFID tag and then after assigned to a shelf. During packaging, warehouse staff use this reader to register produced items with the of reading and writing of its functions instead of manual product recording. Figure. 2 illustrate the Handheld RFID Reader. 


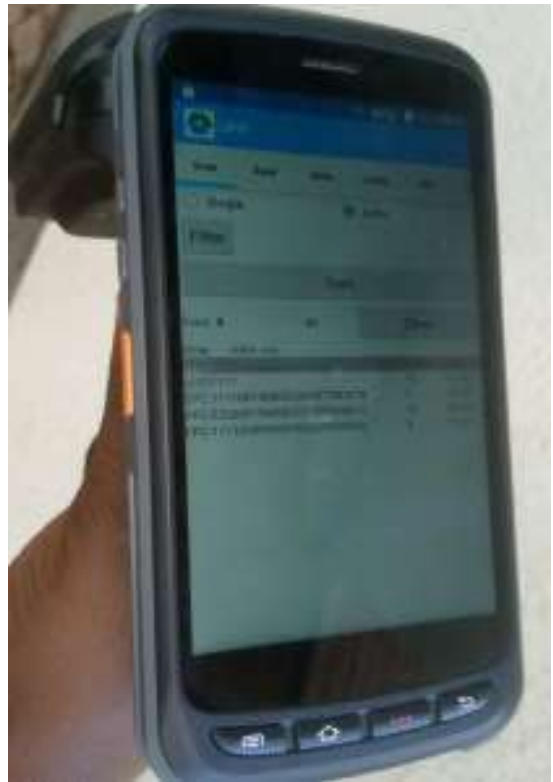

Figure 2. illustration of Handheld UHF RFID reader

\subsection{Automatic pallet and shelf manager}

As discussed previously, based on the practices and operation of this system tags are attached on both pallet and racks of the shelf as shown in the Figure 3. A pallet is a flat structure usually made in wood. It is used to manage the transportation of goods and arrange a good storage policy of goods. Once the pallet is attached to the RFID tag, it is called Automatic pallet. It contains the necessary product information like the price, specification, expiration date, and/or date of production. An Automatic pallet is full when it's the size is equivalent to the shelf where is stored otherwise it has classified as half or empty status.

On another hand a Shelf is a square or rectangular form of wood or other rigid materials placed to any object like a wall or looking like a piece of object made in wood that have a physical space for the storage or display of any items. A certain number of racks were defined for single shelf based on its size and the entire capacity of the warehouse. A rack is a small storage space categorized by an ID number assigned to it usually called Tag Id (TID) since it is embedded in RFID tag of the automated pallet placed on it. By doing this, the efficiency of storage is greatly increased.

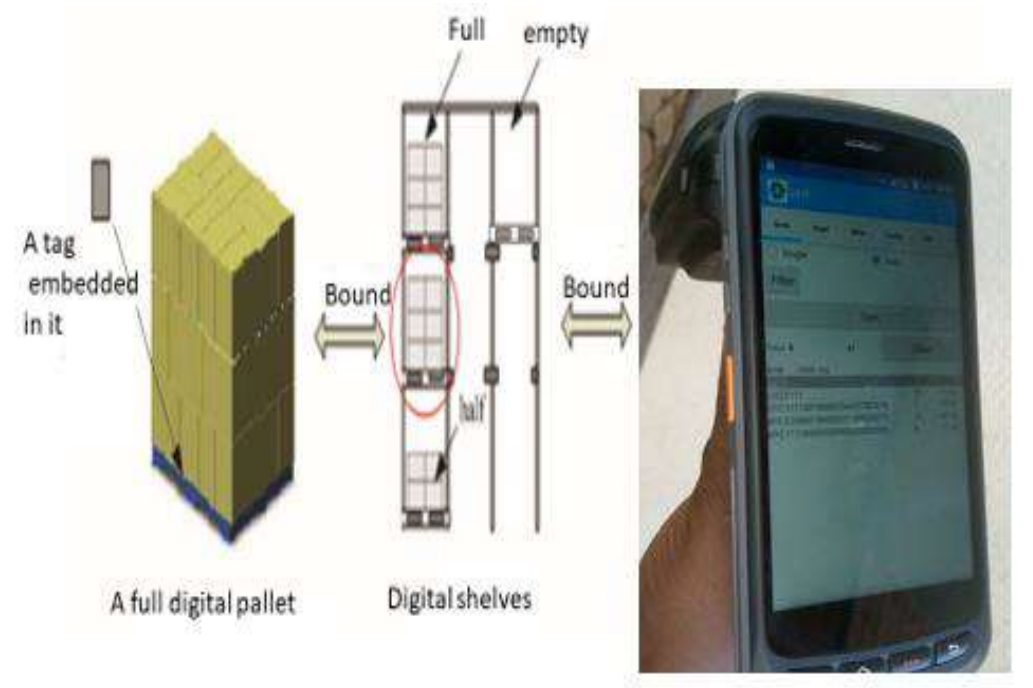

Figure 3. Demonstration of relationship between HRIS, Automatic pallet, and Automatic shelf.

\subsection{Forklift RFID guided system}

Although other additional devices are required to support RFID readers such as barcodes readers, the forklift drivers need sometimes to scan barcode and then input product information in software manually for further processing. It is recommended to process both finished products and their corresponding specification with the help of real time tools in order to maintain the consistency of data. By automating Forklift operations embedded with RFID and wireless network as shown in Figure 4, this disadvantage can be avoided. 


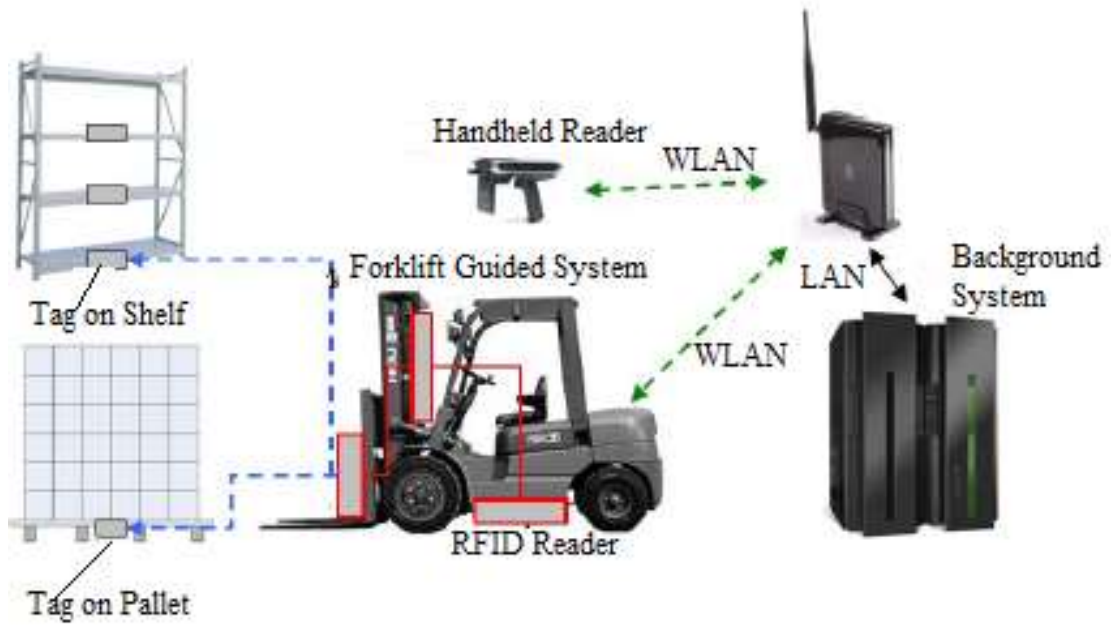

Figure 4. Functionality of RFID based forklift guides system

\subsection{RFID Intermediary Application}

The RFID Based warehouse management uses RFID technology to track products within the warehouse. In this project, an intermediary application is developed between WMS and physical readers. This application provides user interfaces to reader functionalities. It accepts any type of RFID reader after installation of its drivers and connecting with the WMS.

\subsection{Storage/retrieval Manager}

In this system, the storage location plays a significant role in the functionalities of RFID-WMS. The automatic retrieval assignment feature helps to improve the previous warehouse operations to facilitate internal inventory management. The RFID reader helps operators to gather the tag IDs and barcode data of products during the packaging stage before sending them into the warehouse. In addition, if the placed order is not enough to complete the entire pallet, a part of it is delivered, and the remaining data is recorded and updated by the storage and retrieval component.

At receiving stage, goods are scanned by the reader before entering the warehouse for the storage location stage. In the warehouse, a storage and retrieval algorithm is used to assign the location to the incoming products. Set of rules are predefined in the database in such a way that each shelf has a status of either occupied or free. After choosing the storage (assign an item to a rack), this component will retrieve and lock that shelve to avoid another assignment and upgrade its status in the database. The below steps summarize storage operations procedures illustrated in Figure 5:

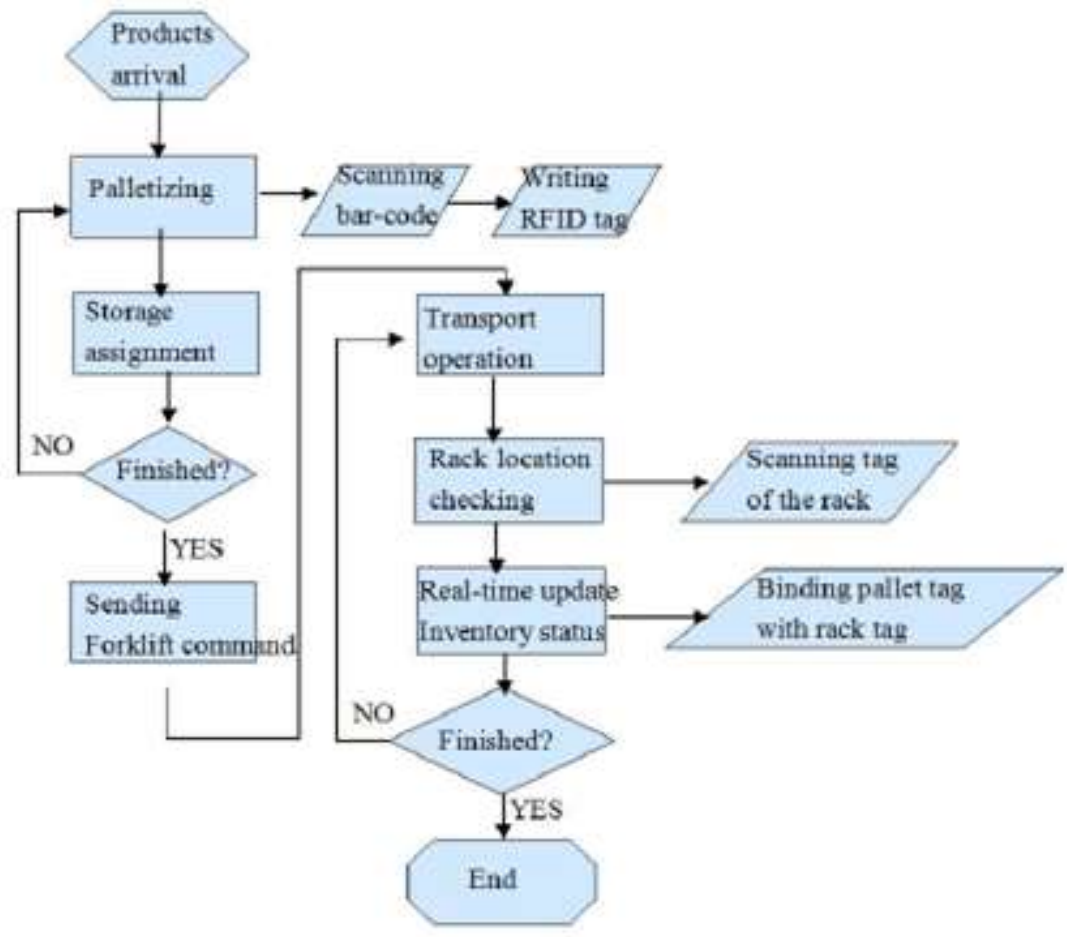

Figure 5. Flow chart of storage procedure 


\section{Algorithm used for Storage assignment}

Data Input: enter product specification and date of production, and the size of shelf denoted as T, C and Z separately.

Output data: Let set of empty computerized racks for putting away Automatic pallets be indicated as B and initialized to null value while starting.

Assume, $A=\left\{a_{1}, \ldots \ldots \ldots . . . a_{m}\right\}$ be the set of walkways with storage of the items having same detail $\mathrm{T}$ and the date of production $\mathrm{C}$ within the same racks.

Assume, $A=\left\{\mathrm{a}_{1}, \ldots \ldots \ldots, \mathrm{an}\right\}$ be the set of empty aisles.

Let: $|\mathrm{Y}|$ be the number of empty shelves in $\mathrm{Y}$, where $\mathrm{Y}$ can be $\mathrm{a}_{\mathrm{i}}, \mathrm{a}_{\mathrm{i}}$ or $\mathrm{B}$.

Let: $\mathrm{P}_{\mathrm{k}}(\mathrm{zi})$ be a set of $\mathrm{k}$ empty shelves assigned from passageway zi, zi $\in$ Á $\cap$ A.

start

initialize $\mathrm{B}=$ null

for each $\mathfrak{a}_{\mathrm{i}} \in$ Á

if $|\mathrm{B}|<\mathrm{Z}$ then

if $\left|a_{i}\right|<(Z-|B|$ then

$\mathrm{B}=\mathrm{B} U \mathrm{P}\left|a_{\mathrm{i}}\right|\left(a_{\mathrm{i}}\right)$

else

$\mathrm{B}=\mathrm{B} \cup \mathrm{PZ}-|\mathrm{B}|\left(\mathrm{a}_{\mathrm{i}}\right)$

end if

else

break

end if

end for

for each $a_{i} \in A$

if $|\mathrm{B}|<\mathrm{Z}$ then

if $\left|a_{i}\right|<(Z-|B|$ then

$\mathrm{B}=\mathrm{B} \cup \mathrm{P}\left|\mathrm{a}_{\mathrm{i}}\right|\left(\mathrm{a}_{\mathrm{i}}\right)$

else

$\mathrm{B}=\mathrm{B}$ UPQ $-|\mathrm{B}|\left(\mathrm{a}_{\mathrm{i}}\right)$

end if

else

break

end if

end for

End

\section{Storage location and retrieval rules}

In order to make the AWMS flexible, different basic criteria for storage location and retrieval assignment was created, taking into account the limitations of existing systems. The technique of storage/retrieval assignment in this system is based various basic Event Condition Action standards that are activated to analyze actions to be triggered at a given time and automatically perform suitable actions.

In practice, various necessities require alternative storage location and retrieval assignment criteria. To do so, the researcher compiled some of the most commonly used rules such as random rule, closest rule, velocity rule, weight rule, identity rule, FIFO, and LIFO rules in practice and demonstrated how, by combining them, this system can be flexible to its requirements.

\section{Algorithm used for retrieval assignment}

Data input: The quantity and specification of electronic shelves required by the orders are denoted by S and Q, respectively.

Output data: a set of Automatic shelves, marked as E, for delivering the Automatic pallets put on them, which is initialized to null before the program starts.

Let: $\mathrm{L}=\left\{1_{1}, \ldots, 1_{\mathrm{m}}\right\}$ be a group of Automatic shelves on a chosen rack with the same characteristic $\mathrm{S}$, which have a higher priority than those in drive-in racks.

Let: $\mathrm{B}=\{\mathrm{b} 1, \ldots, \mathrm{bn}\}$ denote the set of aisles that have stored products with the same specification $\mathrm{S}$, sorted in increasing order of manufacturing date. That means bi has the products having a manufacture date that is earlier than $b_{i}+1$. 
Let: [Y] represent the total number of Automatic shelves in $\mathrm{Y}$ that are not empty, where $\mathrm{Y}$ can be $\mathrm{b}_{\mathrm{i}}$ or $\mathrm{E}$.

Let: $\mathrm{F}_{\mathrm{k}}$ (bi ) represent a collection of k non-empty Automatic shelves assigned from the aisle.

$b_{i}, b_{i} \in B$.

Begin

Initialize $\mathrm{E}=\mathrm{Null}$

If $m>Q$ then

$\mathrm{E}=\mathrm{E} \cup\left\{1_{1}, \ldots, 1_{\mathrm{Q}}\right\}$

Else

$\mathrm{E}=\mathrm{E} U \mathrm{~L}$

End if

For each $b_{i} \in B$

If $|\mathrm{E}|<\mathrm{Q}$ then

If $\left[b_{i}\right]<(Q-[E])$ then

$\mathrm{E}=\mathrm{E} \cup \mathrm{F}_{[\mathrm{bi}]}\left(\mathrm{b}_{\mathrm{i}}\right)$

Else

$\mathrm{E}=\mathrm{F}_{\mathrm{Q}-[\mathrm{E}]}(\mathrm{bi})$

End if

Else

Break

End if

End- for

End

\subsection{Event Processor Manager}

This component helps the WMS to identify the generated events and evaluates them on time. The EPM has two types of events: The basic events and High-level events (HLE). The basic events are those produced by physical devices such as RFID readers while HLEs are events produced by system applications (e.g., WMS).

The constructor function was defined to combine the grouping, filtering, and CEP) functions when the input event is accepted by the event buffer with the help of Event program manager, as illustrated in Figure 6.

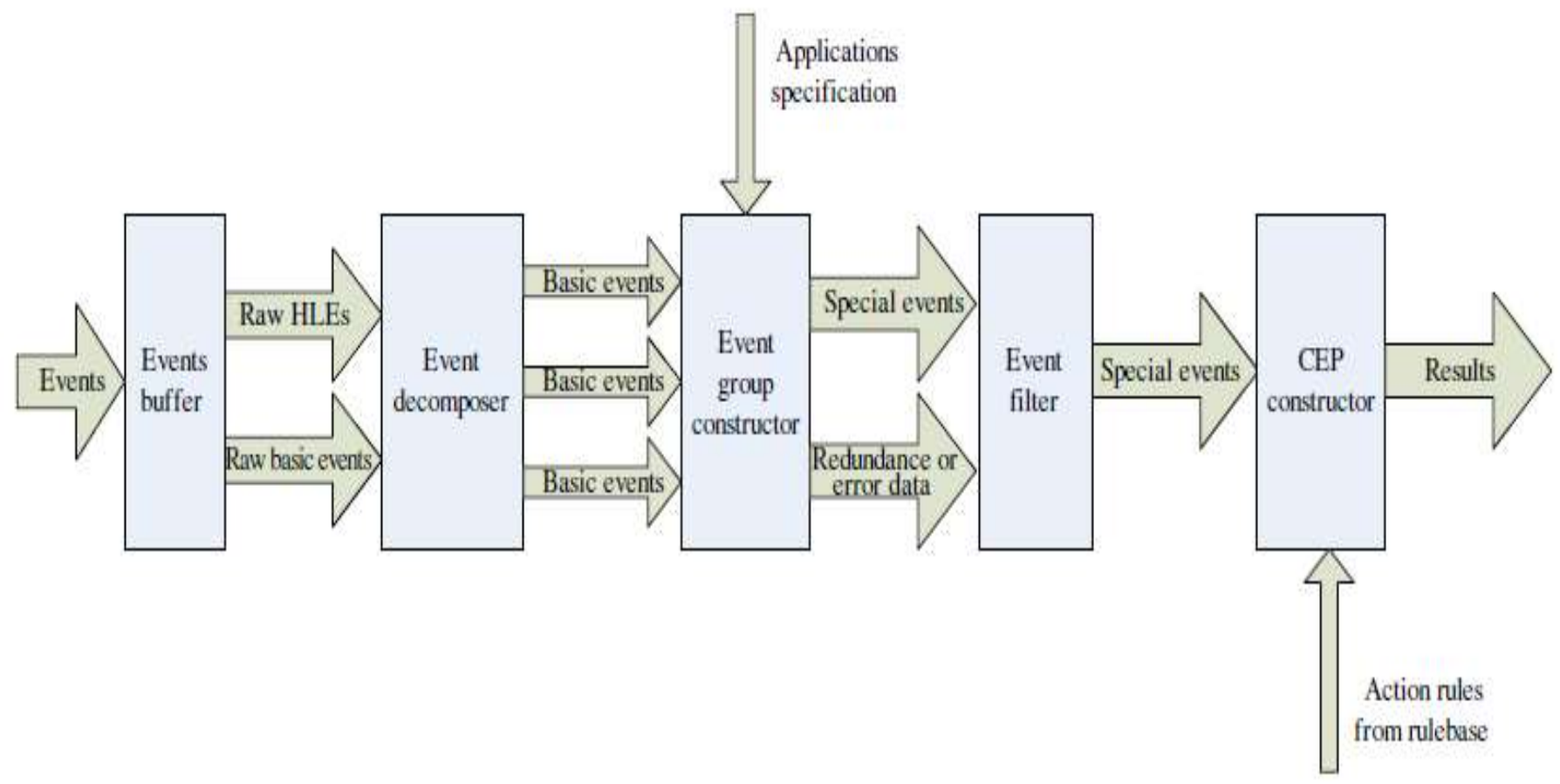

Figure 6. Event Processor Manager Structure.

Since all events got to be decayed into the basic events before being stacked into the event program, they are gathered into extraordinary events for instance capacity task or overhauling information after going to the event constructor. In case two or more same events, the filter is called to remove them and rectify any other mistakes which will happen within the system with the assistance of the constructor, and at long last, the results are sent to AWMS. For instance, if a packaging event is loaded, the 
decomposer breaks down it into an RFID check with Tag IDs and a barcode scan with barcode data. Both the RFID scan and barcode events are converted into basic events at the packaging stage and after they are grouped into the special event after reaching the event group constructor i.e. Being called by the application.

The process of storage/retrieval assignment, as described in the preceding section, is based on ECA's triggered based on corresponding events. An ECA rule must good enough to satisfy the complexity of the events, originating from numerous fundamental ones based on corresponding algebra, in order to be effective in a wide range of applications [16]. In this section, we'll describe how we classify and define the fundamental events in our AWMS, as well as how they combine complex events with logical operators and trigger the occurrence of others.

Usually, an event can be expressed as a tuple 5R, S, T according to [17] and [18]. The label dimension, L, is used to categorize them and contains information about the events that occur. The spatial dimension $\mathrm{S}$ denotes where the event takes place, while the time dimension $\mathrm{T}$ denotes when it takes place. The granularity of the location dimension is determined by the needs of the user. For example, a warehouse manager's location could be a physical position in the warehouse, such as the entrance, or an Automatic shelf location defined by the shelf ID.

The location, on the other hand, might be a supply chain node, such as a distributor, wholesaler, or merchant, from the perspective of the supply chain. Similarly, the time dimension can be a time interval or a time point described in hours or days. Consider the standardization of events: a database event stating that "the production date of the cigarettes on Automatic Shelf K is August 22, 2008 " can be written as:

$\mathrm{E} 1=<\mathrm{R}=$ Shelf_Status,

R. Shelf ID= 'K'

R. Shelf Date= '2008-08-22',

R. Shelf Type = 'cigarettes',

$\mathrm{S}=$ 'Active Database'

$\mathrm{T}=\mathrm{t} 1>$

Where $\mathrm{t} 1$ is the moment at which Active Database detects and reports E1. The created events are divided into two categories: basic events and high-level events. A fundamental event is one that cannot be decomposed and may be observed directly by readers, clock monitors, active databases, or other sensors. A high-level event (HLE), on the other hand, is a collection of several basic events or multiple HLEs that cannot be directly monitored but can be decomposed into basic events.

The processing unit in the processor is the basic event, according to the EPM's research. As a result, in order to make complex event processing easier in EPM, we need to provide a classification of our system's events, particularly the basic events.

In contrast to [19] classification, we present a more extensive classification in our AWMS, where a basic event can be generated in six ways rather than four. The six generated events in our system are RFID scan, Barcode scan, Clock, Database, Update, and Confirm.

\subsection{Handheld Reader Integrated system (HRIS).}

This subsystem is developed separately from other subsystems. It is embedded in a UHF handheld RFID reader which will be fixed on the forklift. It consists of a command queue that is in charge of different commands used in the system. Since the HRIS is attached to a forklift truck moving around in the warehouse, it helps to collect data automatically when passes around the reader and communicate with AWMS to update inventory data in the database. Forklift drivers are not allowed to transport more than one pallet at the same time. They transport them one by one to avoid some mistakes that may happen. This implies that a trucker vehicle(forklift) should runs some commands if previous one has been completed. Besides, HRIS communicates with AWMS that a given command has been executed to avoid double execution of a given command. See the sequence diagram shown in Figure 7 for more details on the functionalities of the transaction series mentioned above. 


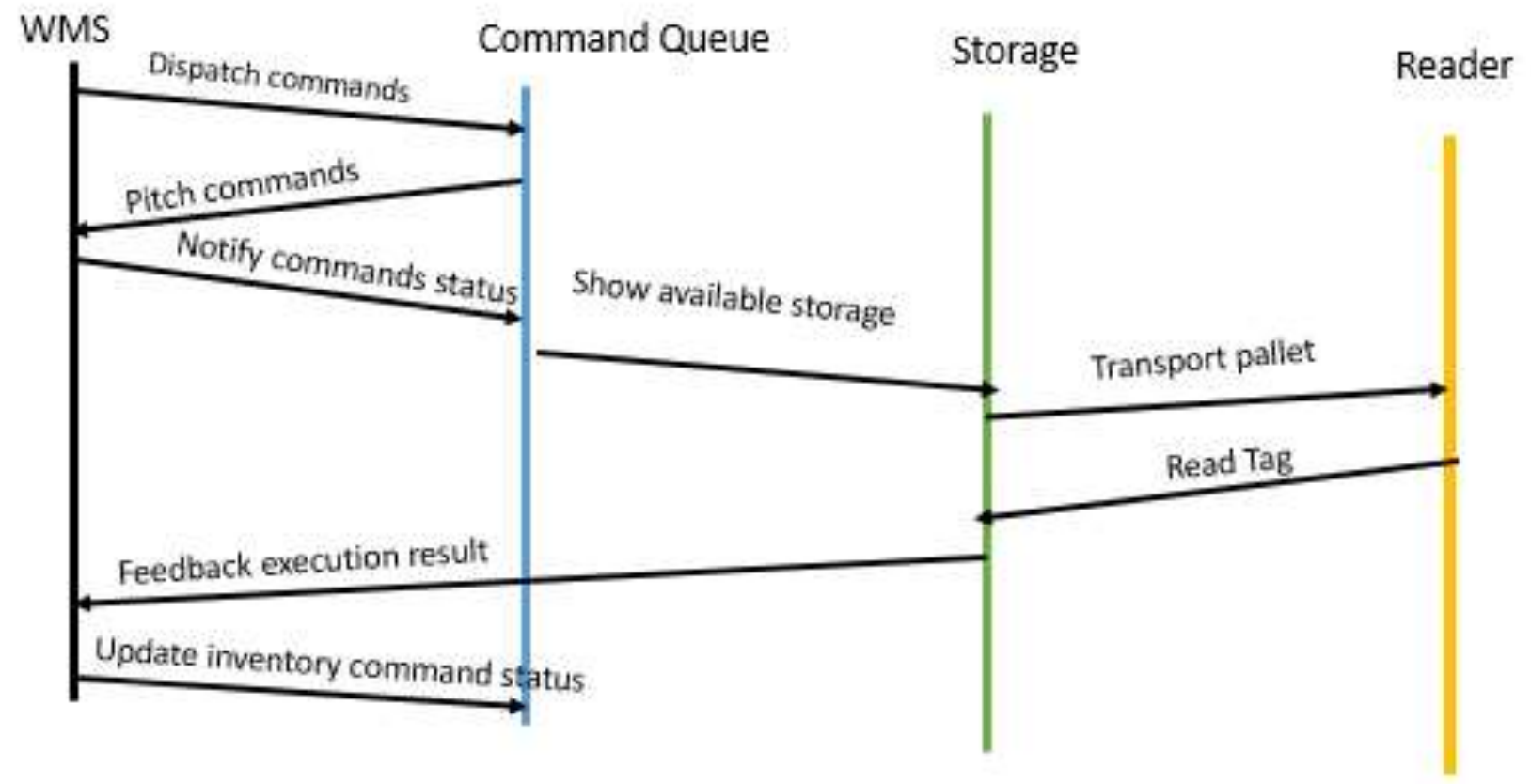

Figure 7. The diagram showing process of HRIS transactions.

\subsection{Back-End Module}

This component has two primary parts which are a dynamic database and a house of rules. This dynamic database can distinguish all exercises and any circumstance happening in a transaction of the framework and respond to them without any user interaction or indeed application demand. As result, it can offer assistance to the system to prepare and react to an event interior or exterior of it [15]. The second portion of the back-end module is the Event Commands Action. It summarizes the essential rules required within the framework to facilitate the execution of diverse transactions in real-time. The application of the rule-based will offer assistance to perform the following activities within the rulebase: add a rule, modify a rule, or delete a rule.

\section{RESEARCH CASE STUDY AREA}

The study was carried out at ROK industries in capital city of Kenya. ROK industry is established in the year 2010 and starts its operations in 2011. In the beginning, the company started its operations by manufacturing candles with mere 20 Employees. Today ROK Industries LTD, is a leading manufacturer of Petroleum Jellies, Milking Jellies, Candles, Tapes, Glucose products among other many products. ROK takes pride in manufacturing and supplying high-quality products that meet international safety standards for the Kenyan Market and the entire Eastern Africa Region. the company's warehouse facility occupies a small land area of almost 500 square meters. This product depot houses nearly 5 stocks of various elements from blank products to finished products, which are delivered, disposed of, and accounted for every day. It has five separates warehouses with different types of products. The system testing and validation ware in in a ROK' warehouse.

\subsection{Analysis of current Warehouse Process}

The Automated warehouse management is a continuous concept that manufacturers, the facilities of production, and supply chain elements are proposing to increase the efficiency and lower high cost of warehouse activities. In this manner, a modern warehouse management framework is under development for ROK industries asset tracking utilizing RFID technology. In this warehouse, all incoming items are within the shape of cartons with a glued barcode to recognize them uniquely. Before the goods are shipped, operators must check each item's barcode one after another to gather necessary information of future when they are needed. All activities in this warehouse are done manually, and goods are stored on the ground in the warehouse without any defined rule.

In a commonplace stream of warehouse activities, after packaging, products are brought in the warehouse which is known as receiving process. Once the products come into the warehouse, the operator makes an arrangement based on his/her memory and own experience to locate them with storage space. When an order is placed, the operator has the task of remembering the location of the ordered items. At that point, some operators should be around to carry these items to the delivery area. Once the products pass through the exit gate, operators scan them one by one using barcodes scanners. During scanning barcodes data, some mistakes may happen. For that reason, one operator should use a computer application to check whether something wrong happened and make a manual inventory report at the end of the day. After a clear explanation of existing warehouse activities, some proposals have been raised for the improvement of the warehouse operations. Specifically, the following angles have been tackled and described in the analysis of the requirements stage: the storage process, delivering, barcodes scanning process, Automaticizing pallets (by assigning RFID tags) and inventory management process. 


\subsection{Requirements analysis}

By analyzing the discussions with warehouse managers and warehouse operators, we outlined the necessities of the system. See Table 1 for more details on these discussions.

After examination of their necessities, the researcher proposes the RFID- AWMS framework. In order to keep a proper use of warehouse capacity, the drive-in rack was proposed during products shaping in order to prevent some operational errors and problems, operators convey items on pallets, with RFID labels attached to the pallet rather than the product, as this is the most cost-effective way of RFID adoption.

Table 1. Requirement for RFID_AWMS

\begin{tabular}{ll}
\hline Employee & Requirements \\
\hline Warehouse Manager & Applying drive in racks to increase warehouse space \\
& Improve warehouse procedures through the use of RFID tags \\
& Record keeping \\
Warehouse Operator $\quad$ Having a visualized warehouse Inventory information & Recording stock in and Stock out data \\
& Providing a quick inventory reports \\
& provide an automatic decision for storage assignment \\
\hline
\end{tabular}

\subsection{Warehouse Layout Design}

The previous warehouse design has no well-structured layout. Based on the analysis requirements of the RFID-AWMS, the drivein racks were proposed in designing the layout of the warehouse before implantation RFID. The layout of the entire warehouse designed using the drive-in rack shown in Figure 8 has six layers. The warehouse length is eight racks in depending on the capacity of trucks.

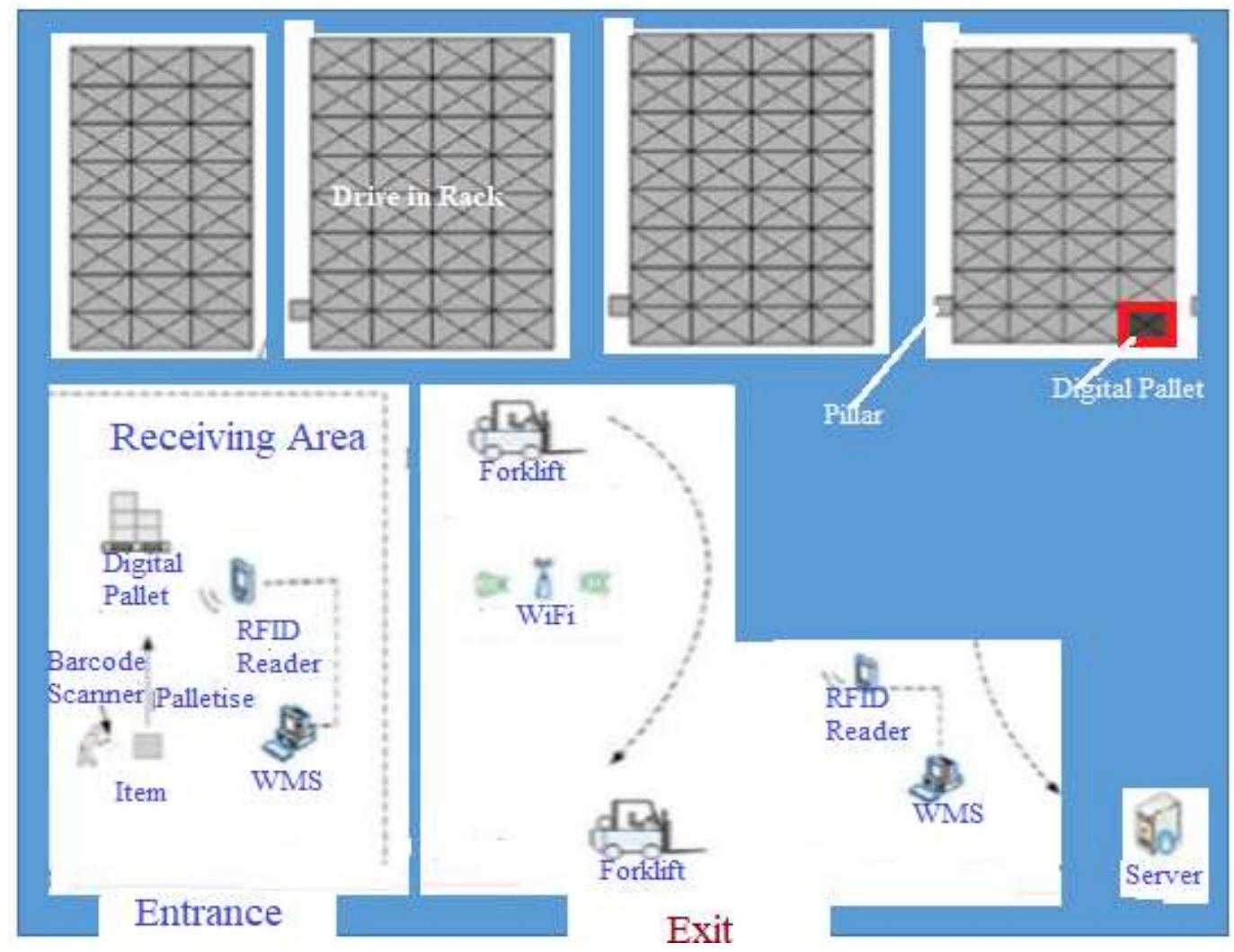

Figure 8. The warehouse layout 
According to [21], in order to have good readings of the RFID reader, it's better to place the reader in the eyesight position to facilitate forklift reading and scan effectively. The first reader is fixed at the entry of the warehouse to scanning of the incoming products, and the second reader on the exit gate to read outcoming items.

The receiving products are palletized and stored in their corresponding locations, and operations of collection data are done by barcode scanners and RFID readers at the same time.

Once the order is completely ready to ship, the forklift drivers transport it to the vehicle for shipping, and once pass through the reader on the gate, the reader 2 scans all data and update the information in the database. The long-range RFID reader has been used to facilitate the readings of pallets at a certain distance.

\subsection{System design}

After analysing the requirements of the RFID-AWMS, the researcher classified its functionalities into the following five parts: human resources subsystem, receiving subsystem, ordering subsystem, shelf management subsystem, and handheld reader integrated subsystem as described below.

\section{a) Human Resources Management Subsystem}

The human resource tool in this study helps warehouse managers to manipulate the operator's performance and the daily evaluation by analysing the recorded information for a given date.

\section{b) Stock in Subsystem}

The receiving part of this study has numerous functions. First, it helps to know the storage location of incoming items on a realtime basis concerning storage rules in rulebase.

Secondly, the warehouse user may use this subsystem to create a storage space with the help of storage commands from rulebase and send them to the HRIS for forklift reader to implement them. Lastly, once this subsystem receives a confirmation from HRIS, it automatically upgrades data in the database.

\section{c) Stock out Subsystem}

This subsystem is for doing the inventory management within the warehouse to solve the problem of ordering and shipping activities. It provides the capability of retrieval assignment after ordering a given pallet from its storage and communicates with AWMS to update data in the database. In case of incorrect pallet detection, this subsystem can know it by comparing and matching its tag Id with the tag assigned to the shelf and provide an alert to the forklift drivers. See the relationship of RFID-AMS in Figure 9.

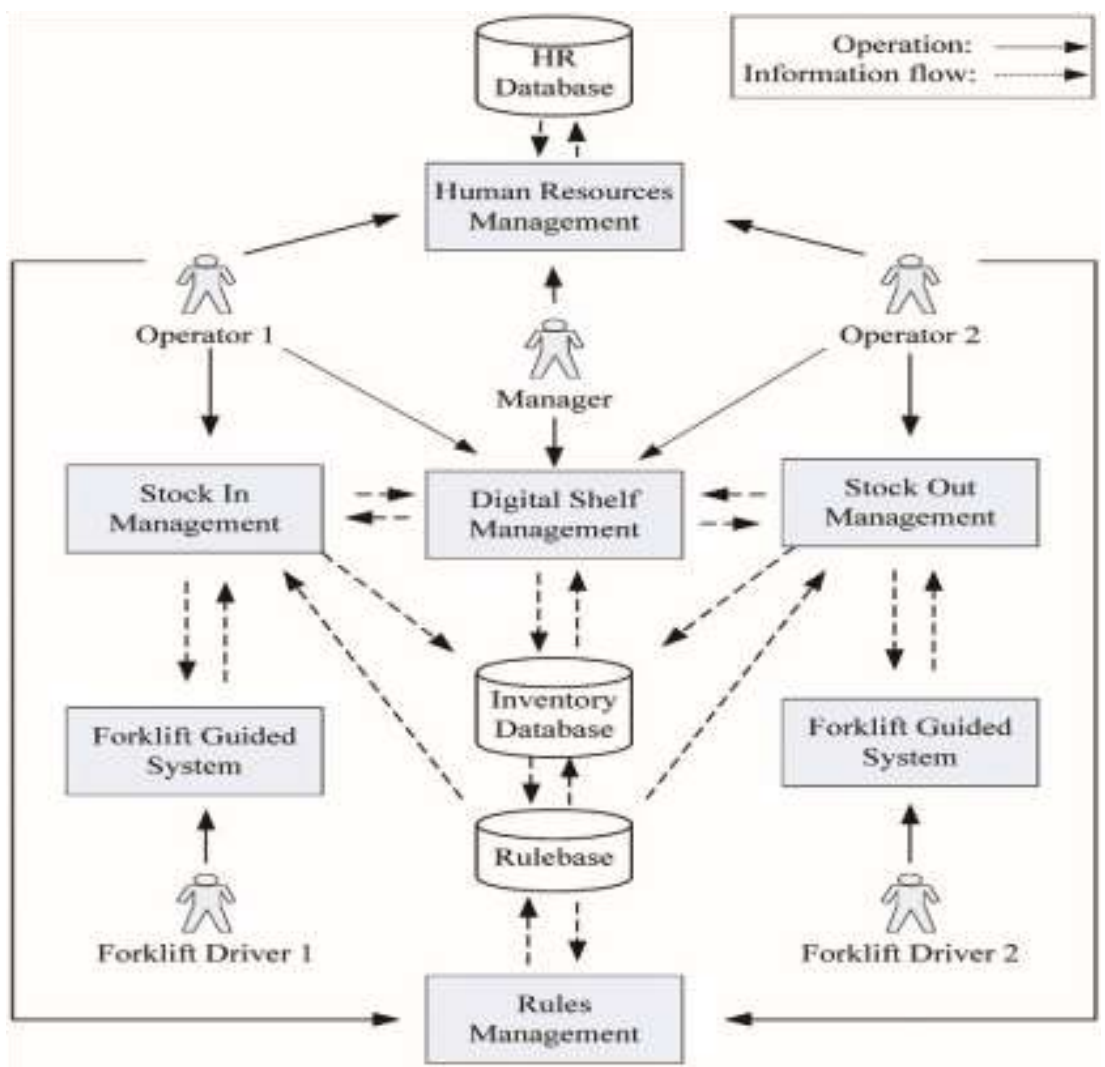

Figure 9. Subsystems functionality in the new system 


\section{d) Shelf Management Subsystem}

The shelf management helps warehouse managers to know the status of storage location and an overview of the entire warehouse inventory management process on time. Moreover, this part of the system provides the accurate inventory statistical report that contains the beginning of inventory data, receiving, ordering, and product quantities concerning the specification of each product and the operator's details and also the time it takes to complete a transaction and the end of inventory data. In addition, this function also helps in monitoring the rack's status. When there is one pallet in the passageway of drive-in racks and maybe a specific rack with an extra shelf, the system provides an alert for completing the remaining pallet to the temporary space for proper use of drive-in racks.

\section{e) Handheld Reader Integrated System}

This subsystem is developed within the handheld UHF RFID reader. It is fixed on the forklift to assist the execution of different commands. These commands are executed when the handheld scans a pallet tag and communicates with AWMS to update the information in the database. Since the items are stored in the drive-in racks, the LIFO rules help execute commands in this subsystem during ordering products. This part of the system has the added value of communicating with other subsystems with the help of a wireless network.

\section{f) Rules management subsystem}

This module is design to provide set of rules to help warehouse users to perform basic functions. In addition, this subsystem allows the user to modify some rules based on the needful of company's vision.

\subsection{System implementation}

According to the structure and the design of this system, the RFID-based warehouse management system is developed using Rich Client Platform(RCP), which facilitates visual studio plug-in architecture. It helps in developing C\# application that can be compatible with other applications developed using any other platform. With the help of a wireless network, the use of TCP/IP and socket technology contributed to analysing the communication between subsystems.

\subsection{Results and Discussion}

Before implementing this system, the ROK warehouse was time-consuming with a lot of workers. The packaging process is done in the provided workshop rooms, then after the items are transported into the warehouse by operators. The operators decide where to store goods based on their own experience which may cause the misuse of warehouse space. After using the RFID-based warehouse management system, the following automated features have been added to the system's functionality. These features are storage and retrieval assignment, automatic inventory management within the warehouse, forklift operations for loading and offloading, and the impact of using these new features is a lower number of workers because of the automation of most activities. For instance, the internal inventory is monitored by AWMS through a handheld reader integrated system. A Drive-in rack facilitates warehouse activities. The FIFO rule helped in receiving finished goods by respecting the storage location algorithm.

As a result, the mistakes made by the operators are significantly reduced. In addition to that, warehouse managers can easily monitor inventory in real-time. Besides, there is no need for operators to move around in the warehouse locating product storage. The storage assignment is a job of a single person sitting on the front of the computer with only a single click. Since products are transported in form of a pallet, it is not necessary for the operator to check barcodes one by one and also to verify whether the picked item is the one targeted. This is the task of AWMS through HRIS fixed on forklift passing by the reader and collects the necessary information. The comparison between warehouse operations before and after the implantation of RFID-AWMS is summarized in the following essential elements in Table 2:

\section{(i) Size of warehouse}

According to the table2, it is obvious to tell you that the distribution centre space is managed by $55,5 \%$. This is because of the utilize of drive-in racks.

\section{(ii) Number of workers in the warehouse}

After implementing RFID-AWMS, the interactions between human being in the warehouse has been reduced by half compared to the old system operations. By clear understanding the previous warehouse operations in Section 4.2 and the new modern way of storage location assignment in Section 4.6; it is clear to announce the reduction of employees due to the following reasons: no person is carrying goods in the warehouse, goods are carried by forklift,

no user in charge of storage location assignment this is done storage/location module, and none is scanning barcodes, it is the task of RFID reader through the communication with HRIS. Therefore, I can conclude by saying that there is a reduction of half of the labour works. 


\section{(iii) Loading and offloading time}

Based on the mathematical calculations, it is clear that the usual loading and offloading time is reduced from $60 \mathrm{minites}$ to 20 minutes. This difference comes from the time that operator uses to move around in the warehouse looking for storage of items, scanning barcodes, and carrying products to vehicles for shipping.

5) Inventory accuracy

After implementation of the RFID-AWMS, the augmentation of inventory accuracy is illustrated from $80 \%$ to $99 \%$.

Table 2. Comparison of warehousing performance with and without RFID_AWMS

\begin{tabular}{lll}
\hline & Before RFID_AWMS & $\begin{array}{l}\text { After } \\
\text { RFID_AWMS }\end{array}$ \\
\hline Warehouse capacity & 7000 & 11100 \\
Manpower Loading & 10 & 4 \\
Average loading time & 50 minutes & 18 minutes \\
loading ration & 1000 cartons & 500 cartons \\
Inventory accuracy & $72.8 \%$ & $99 \%$ \\
\hline
\end{tabular}

This benefit is described based on misplacement and transaction errors. Figure 10 explains statistical data of the inaccuracy of the monthly inventory based on the requirement analysis of the RFID-WMS as shown in figure 10. Before implementing this system, the inaccuracy of the inventory management was mainly caused by misplacement as illustrated in figure 10(a). This is because the operator was doing jobs manually and the transportation of product with the warehouse. However, after using this system, figure 10(b) demonstrate that the disarrangement of products within the warehouse has been reduced.

Before RFID-AWMS.

(a)

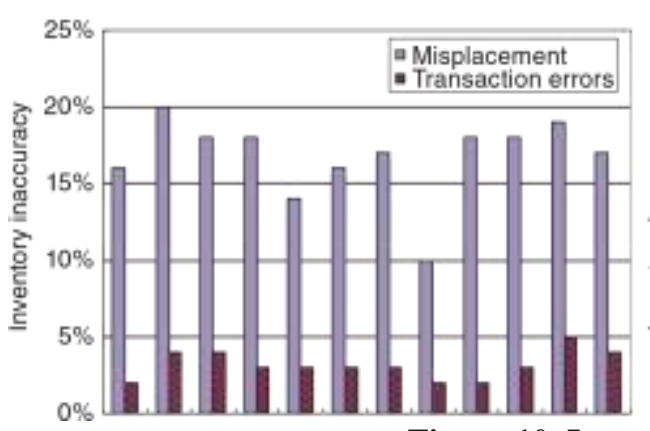

After RFID AWMS.

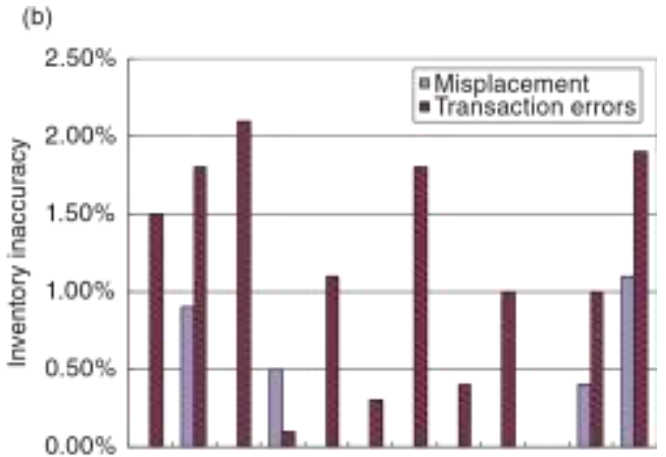

Figure 10. Inventory comparison

The comparison of the transaction errors, before implementing RFID, the author may conclude by saying that this is caused by mistakes made by the barcodes scanners at the time of inventory management or none accurate readings. The RFID-AWMS illustrates an overall $97 \%$ read rate of the tag on the pallet.

The findings of the RFID_AWMS shows that this system might improve traceability and visibility of products and processes, increase efficiency and speed of processes, improve information accuracy and might decrease inventory losses.

\section{CONCLUSION}

The goal of the development of this system was to improve warehouse operations with the help of RFID technology. It was achieved after reaching the visualization of inventory management within the warehouse and the automatic storage and retrieval assignment with a successful integration of UHF RFID reader. With the assistance of RFID technology, the Automatic pallet and shelf are implemented. All items and their corresponding storage location can be gathered together and trucked uniquely. Through the analysis of the functionality of the developed system, we can say that the warehouse operations, the manipulation of storage location, the increment of the precision of inventory, small number of workforce, reduction of loading, and offloading time was improved effectively. The cost of implementation of this system is cheaper compared to its benefits. The designed system is developed based on the existing functionalities of the existing warehouse with the additional features such as handheld reader integrated system used to manage internal inventory, the clarification and differentiation of invents helped in the adaptation of the 


\section{International Journal of Advances in Scientific Research and Engineering (ijasre), Vol 7 (8), August -2021}

system effectively, finally, the application of Event Commands action mechanism helped a lot in defining the rules of storage/retrieval algorithm.

\section{REFERENCES}

[1] Gaukler, G. M., Seifert, R. W., \& Hausman, W. H. (2007). Item-level RFID in the Retail Supply Chain. Production and Operations Management, 16(1), 6-8. https://doi.org/10.1111/j.1937-5956.2007.tb00166.x

[2] Goksoy, A., Vayvay, O., \& Ergeneli, N. (2013). Gaining Competitive Advantage through Innovation Strategies: Application. American Journal of Business and Management, 2(4), 304-321. https://doi.org/10.11634/216796061302463

[3] Spina, D., Di Serio, L., Brito, L., \& Duarte, A. (2015). The Influence of Supply Chain Management Practices in the Enterprise Performance. American Journal of Management, 15(2), 10-18.

[4] Boenzi, F., Digiesi, S., Facchini, F., Mossa, G., \& Mummolo, G. (2015). Sustainable Warehouse Logistics: A NIP Model for non-road Vehicles and Storage Configuration selection. Proceedings of the Summer School Francesco Turco, Industrial Systems Engineering, 15(3), 5-8. https://doi.org/10.11634/21679606

[5] Asif, Z., \& Mandviwalla, M. (2005). Integrating the Supply Chain with RFID: A Technical and Business Analysis. Communications of the Association for Information Systems, 15. https://doi.org/10.17705/1cais.01524

[6] Suryanto, T., Haseeb, M., \& Hartani, N. H. (2018). The correlates of developing green supply chain management practices: Firms level analysis in Malaysia. International Journal of Supply Chain Management, 7(5), 12-14.

[7] Ballard, R. L. (1996). Methods of inventory monitoring and measurement. Logistics Information Management, 9(3), 4-9. https://doi.org/10.1108/09576059610116653

[8] Moh, M., Walker, Z., Hamada, T., Su, C., \& Range, R. (2005). A Prototype on RFID and Sensor Networks for Elder Healthcare: Progress Report. 70-75.

[9] Atali, A., Lee, H., \& Özer, Ö. (2011). If the Inventory Manager Knew: Value of Visibility and RFID under Imperfect Inventory Information. SSRN Electronic Journal. https://doi.org/10.2139/ssrn.1351606

[10] Delen, D., Hardgrave, B. C., \& Sharda, R. (2007). RFID for better supply-chain management through enhanced information visibility. Production and Operations Management, 16(5). https://doi.org/10.1111/j.19375956.2007.tb00284.x

[11] Attaran, M. (2007). RFID: An enabler of supply chain operations. Supply Chain Management, 12(4), $249-257$. https://doi.org/10.1108/13598540710759763

[12] McFarlane, D., \& Sheffi, Y. (2003). The Impact of Automatic Identification on Supply Chain Operations. The International Journal of Logistics Management, 14(1), 1-17. https://doi.org/10.1108/09574090310806503

[13] Viegas, C. V., Varvakis, G., \& Selig, P. M. (2014). Strategic Management Accounting (SMA) and Green Supply Chain Management (GSCM): Advances and challenges for integration in recent academic research. In Process Control: Theory, Applications and Challenges.

[14] Pane, S. F., Awangga, R. M., \& Azhari, B. R. (2018). Qualitative evaluation of RFID implementation on warehouse management system. Telkomnika (Telecommunication Computing Electronics and Control), 16(3), 1303-1308. https://doi.org/10.12928/TELKOMNIKA.v16i3.8400

[15] Qiao, Y., Zhong, K., Wang, H., \& Li, X. (2007). Developing event-condition-action rules in real-time active database. 
International Journal of Advances in Scientific Research and Engineering (ijasre), Vol 7 (8), August -2021

Proceedings of the ACM Symposium on Applied Computing, 511-516. https://doi.org/10.1145/1244002.1244120

[16] Wang, H., Chen, S., \& Xie, Y. (2010). An RFID-based Automatic warehouse management system in the tobacco industry: A case study. International Journal of Production Research, 48(9), 2513-2548. https://doi.org/10.1080/00207540903564918

[17] Poon, T. C., Choy, K. L., Chow, H. K. H., Lau, H. C. W., Chan, F. T. S., \& Ho, K. C. (2009). A RFID case-based logistics resource management system for managing order-picking operations in warehouses. Expert Systems with Applications, 36(4). https://doi.org/10.1016/j.eswa.2008.10.011

[18] Li, S.G. and Kuo, X., 2008. The inventory management system for automobile spare parts in a central warehouse. Expert Systems with Applications, 34 (2), 1144-1153.

[19] Dutta, K., Ramamritham, K., Karthik, B., \& Laddhad, K. (2007). Real-time event handling in an RFID middleware system. Lecture Notes in Computer Science (Including Subseries Lecture Notes in Artificial Intelligence and Lecture Notes in Bioinformatics), 4777 LNCS. https://doi.org/10.1007/978-3-540-75512-8_17

[20] Tan, C. W., \& Goh, A. (1999). Implementing ECA rules in an active database. Knowledge-Based Systems, 12(4). https://doi.org/10.1016/S0950-7051(99)00028-3

[21] Choy, K. L., Chow, K. H., Moon, K. L., Zeng, X., Lau, H. C. W., Chan, F. T. S., \& Ho, G. T. S. (2009). A RFID-casebased sample management system for fashion product development. Engineering Applications of Artificial Intelligence, 22(6). https://doi.org/10.1016/j.engappai.2008.10.011 